\title{
O ESPÍRITO DE COMPROMISSO DO DIREITO DAS SUCESSÕES PERANTE AS EXIGENCIAS INDIVIDUALISTAS DE AUTONOMIA DA VONTADE E AS SUPRA-INDIVIDUALISTAS DA FAMÍLIA. HERDEIRO E LEGATÁRIO ${ }^{1}$
}

\author{
Antonio Junqueira de Azevedo \\ Professor Titular da Faculdade de Direito da Universidade de São Paulo, \\ Ex-Diretor da Faculdade de Direito da Universidade de São Paulo
}

\begin{abstract}
Resumo:
O texto trata da difícil distinção teórica entre herdeiro e legatário, questão de suma importância no Direito das Sucessões. A pesquisa inicia-se com as origens do problema e estende-se até os dias atuais, buscando uma melhor solução para a questão.
\end{abstract}

Abstract:

This text treats, in detailed way, of the distinction between heir and legatee, subject of highest importance in the Right of the Successions. The research begins with the origins of the problem and extends until the current days, looking for a better solution for the subject.

Unitermos: Direito das Sucessões; familia; herdeiro; legatário.

O Direito das Sucessões, tal e qual vigora no ordenamento brasileiro e no dos países ocidentais, resulta de distantes, e contraditórias, origens. Fundamentado largamente no Direito Romano (clássico e pós-clássico), em que predominava a sucessão testamentária, de caráter individualista, mas também influenciado profundamente pelo Direito germânico, de espírito comunitário, inteiramente oposto à autonomia da vontade, viu o Direito das Sucessões, durante a Idade Média, acrescentar-se, a ambas essas camadas, o Direito Canônico. Este, de resto, pela própria índole, já mantinha, em si mesmo, frágil equilíbrio entre as exigências religiosas de proteção à pessoa humana (e, portanto, exigências individualistas) e à família (o que vem a dar em posições supra-individualistas). 
" 'A sucessão causa mortis é um dos campos' em que foi mais viva e diremos quase dramática - a luta entre o fator germânico e o romano, eis que os dois partiam de concepções absolutamente opostas seja da família seja da relação jurídica sucessória. E, de fato, enquanto o primeiro conhecia e reconhecia somente os 'Bluterbe', isto é, os herdeiros de sangue, de forma que o indivíduo não podia testar, o segundo, pelo contrário, sustentava o princípio da mais absoluta liberdade de dispor dos próprios bens com o ato testamentário; enquanto aquele limitava a sucessão a bens determinados, em cuja esfera se restringiam os deveres de sucessor, este, pelo contrário, a alargava a todo o patrimônio do defunto (omissis). Mas é lícito indagar no nosso entendimento dentro de que limites se deva conter a importância desse conflito histórico, eis que, de fato, aqueles autores que restringiram o interesse científico, que oferece a história do direito hereditário, à luta entre os dois direitos o germânico e o romano pecaram por evidente unilateralidade. $E$, de fato, esses autores descuidaram e muito um terceiro fator, que é precisamente o direito canônico" ${ }^{2}$

Desse amálgama de fontes diversas, resultou um conjunto de normas que, para qualquer estudioso do espírito do Direito das Sucessões, se revela uma solução de compromisso. Nas palavras de Radbruch ${ }^{3}$ "o atual direito sucessório não passa afinal dum compromisso entre sistemas e principios opostos" E continua: "Não só acham nele, por assim dizer, soldadas umas às outras formas sucessórias diversissimas a liberdade de testar e a sucessão intestada, a partilha forçada e a indivisão também forçada entre co-herdeiros como se acham igualmente aí intercaladas finalidades inteiramente opostas, individualistas, sociais e familiares, obedecendo, para mais, estas últimas, a concepções diferentes da família, ora também individualistas, ora supra-individualistas"

Especificamente no Direito brasileiro, as soluções de compromisso, quando não as contradições, avultam: à liberdade de testar (autonomia da vontade) opõe-se a legítima dos herdeiros necessários (proteção à família); à idéia de função econômica, que justificaria a sucessão pela continuidade da unidade dos bens, apresenta-se, em contrário, a regra da partilha, que impõe divisão; e, principalmente, ao herdeiro, muitas vezes visto como continuador do de cujus, apresenta-se o

2. Emílio Bussi, "La formazione dei dogmi di diritto privato nel diritto comune" Cedam, Pádua, 1971, p. 113 - traduçāo nossa.

3. "Filosofia do Direito", trad. de Cabral de Moncada, 4" ed., Arménio Amado Editor, Coimbra, 1961, v. II, p. 74. 

vontade e as supra individualistas da familia. Herdeiro e Legatário

legatário, mero recebedor de bens. Tudo isso torna o Direito das Sucessões muito mais complexo do que nos é apresentado usualmente nos manuais de Direito Civil.

No prefácio de obra de Direito comparado, ${ }^{4}$ Henri Batiffol assim se expressa: "Petijean se prendeu à primeira parte de sua tarefa, partindo da experiência que lhe forneceu sua participação na regulamentação de numerosas sucessões franco-inglesas. Impressionado pelas divergências de métodos e soluções, quis se remontar à sua causa profunda. Já se sabia que, no conjunto, o contraste consiste em que o Direito inglês encara a sucessão como uma devolução de bens, enquanto que o Direito francês acentua, em primeiro plano, a continuação da pessoa" (tradução nossa). Ora, a "causa profunda" nos ordenamentos francês e inglês, não é, no caso do Direito brasileiro, causa única, e sim, causa dúplice, eis que, com as observações que adiante serão feitas, nosso herdeiro, um continuador patrimonial do de cujus, se aproxima do espírito do Direito francês, enquanto nosso legatário, um mero recebedor de bens, do do Direito inglês.

Em geral, os manuais apresentam dois traços para caracterizar a diferença entre herdeiro e legatário: a. o herdeiro é sucessor a título universal; recebe patrimônio ou quota-parte de patrimônio. O legatário é sucessor a título singular; recebe coisa certa e determinada; b. o herdeiro é figura comum à sucessão legítima $\mathrm{e}$ à testamentária, enquanto o legatário é peculiar à testamentária. Nesse sentido, sem preocupação com o nome dos autores (poderiam ser tanto os citados quanto outros), lemos: "Embora campeie certa indecisão no caracterizar e distinguir o legado, este se não confunde com a herança, e o legatário com o herdeiro. A herança compreende a sucessão, legal ou testamentária, in universum ius defuncti, isto é, na totalidade dos bens ou numa quota-parte deles. Legado é peculiar à sucessão testamentária e incide necessariamente sobre uma coisa certa e determinada, o que o classifica como sucessão a título singular, posto que mortis causa" ${ }^{5}$

"Perante a nossa lei, herdeiro é não só o legal, convocado de acordo com a ordem de vocação hereditária, como também o nomeado ou instituído por ato de última vontade. Mas, herdeiro nomeado ou instituído não se confunde com legatário, nem legado se confunde com herança. O legatário recebe coisa determinada e precisa, isto é, porção concreta do acervo hereditário, deixada a

4. "Fondements et mécanisme de la transmission successorale en Droit français et en Droit anglais", de Henri Petijean, L.G.D.J, Paris, 1959.

5. Caio Mário da Silva Pereira, "Instituições de Direito Civil", 6² ed., v. XI, p. 186. 
título singular (res certa), ao passo que o herdeiro aufere todos os direitos patrimoniais do extinto (universum jus), ou fração em todos esses direitos, sem discriminação de valor ou de objeto (omissis). Na sucessão legítima, em que não há testamento, existem apenas herdeiros legítimos; na sucessão testamentária, quanto a porção disponível, podem ocorrer herdeiros instituídos e legatários. Recebem estes coisa determinada, precisa, certa; recolhem aqueles, indeterminadamente, parte ideal na universalidade, embora posteriormente, com a partilha, se restrinjam seus direitos aos bens que lhes forem adjudicados ou atribuidos" ${ }^{6}$

Infelizmente, as duas notas caracterizadoras da diferença entre herdeiro e legatário não são satisfatórias. Daí, aliás, o professor Caio Mário da Silva Pereira, no início da citação supra, observar uma certa "indecisão" da doutrina. De fato, quanto à primeira característica, saber se a sucessão é a título universal ou a título singular é conseqüência de se tratar de herdeiro ou legatário. Há petição de princípio. A nota apontada como diferenciadora é justamente o que se quer saber como resultado final da investigação, e não seu ponto de partida. A característica dá, pois, como sabido o que se quer saber grave vício lógico. Quem determina se alguém é herdeiro ou legatário é o testador, na sucessão testamentária, e o legislador, na sucessão legítima.

Pior ainda é o segundo critério: não só não serve para distinguir as duas espécies de sucessores, como cai em grande erro, porque há também legatário na sucessão legítima, isto é, legatário ex lege, ou por força de lei, tal e qual acontece com o herdeiro. Ambas as figuras podem aparecer quer na sucessão legítima quer na testamentária. Aparece o legatário por força da lei no $\S 2^{\circ}$ do art. 1.611 do Código Civil e no parágrafo único do art. $7^{\circ}$ da Lei n. 9.278, de 1996, eis que, em ambos os casos, o cônjuge supérstite, ou o convivente que remanesce, recebe o direito real de habitação relativo ao imóvel destinado à residência da família. Ora, esse direito real de habitação é bem determinado; trata-se, evidentemente, de legado ex lege e, portanto, normalmente, ocorrente em sucessão $a b$ intestato. Diante disso, compreende-se as severas palavras de Michel Villey: "a ditadura dos manuais nos afunda na ignorância" ("la dictature des manuels nous enfonce dans l'ignorance" Reflexions sur la philosophie et le droit"). 166.

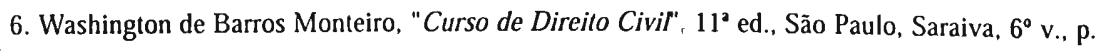


A questão se complica ainda mais, justamente com a hipótese do chamado "herdeiro ex re certa" Aqui, dá-se a vocação à herança à herança, note-se bem sem que o testador indique expressamente uma quota abstrata, mas sim, desde que indique os bens que deverão compor o quinhão do herdeiro.

É sempre da leitura do testamento que se infere a vontade do testador de ordenar o preenchimento, com bens determinados, da quota de cada qual. $\mathrm{Na}$ hipótese de herdeiro ex re certa, apesar da indicação de um bem determinado, não há legado algum. $\mathrm{O}$ art. 588 do Código Civil italiano, em sua segunda parte, é, nessa questão, de clareza meridiana: A indicação de bens determinados ou de um complexo de bens não exclui que a disposição seja a título universal, quando resulta que o testador teve intenção de designar tais bens como quota do patrimônio" ("L'indicazione di beni determinati o di un complesso di beni non esclude che la disposizione sia a titolo universale, quando risulta che il testatore ha inteso assegnare quei beni come quota del patrimonio").

Sobre o herdeiro ex certa, é, por sua vez, ilustrativa a exposição de Trabucchi $^{7}$ Il capoverso dell'art. 588 prevede la possibilità di una chiamata ereditaria nella quale il testatore non indichi la quota astratta, ma i singoli beni che la dovranno comporre; si parla di istituzione di erede ex re certa: il lascito di beni determinati costituisce eredità quando risulti che il testatore ha inteso assegnare quei beni come quota del patrimonio (criterio soggettivo). Vari elementi saranno considerati dall'interprete per ricercare l'intenzione del testatore. Perché ci sia istituzione di erede, deve risultare che il testatore aveva presente tutto il patrimonio in modo da ripartilo tra $i$ sucessori, atribuendo al chiamato la quota risultante dal valore dei singoli beni lasciati, rispetto al valore complessivo dell'asse. Molto spesso si giudicherà come istituzione di erede la disposizione, che è anche frequente nella pratica, con la quale si lascia la totalità dei beni mobili o la totalità degli immobili. Il valore aritmetico della quota si determina in tali casi, a posteriori, stabilendo un rapporto tra $i$ beni di cui si tratta e il complesso delle attività del de cuius"

Se há legatário ex lege e, agora, como vemos, herdeiro em coisa certa, a diferença entre as duas espécies de sucessores mortis causa (herdeiro e legatário) parece desaparecer: afinal, tanto há legatário na sucessão legitíma, quanto há herdeiro que sucede em coisa certa. Além disso, cumpre lembrar que o testador,

7. "Istituzioni di Diritto Civile" 15² ed., Pádua, Cedam, 1966, n. 367, p. 861. 
entre seus bens, pode ter direitos de herança na sucessão de outra pessoa e, justamente, deixar em legado para alguém esses direitos hereditários - quando, então, o legatário, em certo sentido, será sucessor em quota e a título universal. Não é de admirar que Orlando Gomes, ${ }^{8}$ seguindo a Messineo, acabe por adotar uma solução comodista e afirme que "a dificuldade de conceituação conduz a definir o legado por exclusão. Com esse nome, designa-se qualquer disposição testamentária que não signifique instituição de herdeiro" (!).

Para não chegarmos a esse extremo, é preciso antes estabelecer, como pressuposto metodológico, o raciocínio tipológico, ao lado do conceptual. Os conceitos se definem, os tipos se descrevem. Diante de um conceito, ou algo é ou não é; tertium non datur, ou o objeto cai sob a definição, isto é, a ela se subsume, ou não. Exemplar é no silogismo: "todo homem é mortal, ora, Sócrates é homem, logo, Sócrates é mortal" a subsunção, nas duas proposição finais, da idéia "Sócrates" aos dois conceitos "homem" e "mortal" Já diante de tipo, o objeto pode estar mais próximo ou mais distante, sem que necessariamente se tenha que pensar em o objeto estar "dentro" ou "fora" da definição; por exemplo, são notas características do tipo barroco: linhas curvas, elemento surpresa, preenchimento de todo o espaço, distribuição das massas, etc. etc., de tal forma que, de uma construção, pode ser dito que ela é mais, ou menos, barroca que outra. Ora, no mundo jurídico, há muitos séculos, o raciocínio tipológico tem o seu lugar, parecendo até mesmo, muitas vezes, mais adequado que o conceptual, eis que, como escreveu Javoleno, omnis definitio in jure civili periculosa est: parum est enim, ut non subverti posset" (D. 50, 17, 202).

Admitido o pensamento tipológico, menos rígido que o conceptual, vê-se que o herdeiro ex re certa é claramente um herdeiro, -mas não resta dúvida que, no leque de idéias sobre os sucessores, está mais próximo do legatário do que está o herdeiro em quota abstrata (herdeiro de 1/3, 1/4, etc.). Há gradação: legatário, herdeiro em coisa certa, herdeiro em quota abstrata. Essas considerações não podem, porém, levar o jurista atual a tratar o herdeiro ex re certa como legatário; não podem nem mesmo levar o jurista atual a considerá-lo como terceira espécie (esta era a posição, no séc. XIV, de Bártolo: "institutus in re certa non est haeres neque legatarius sed tertia species"). Numa certa altura do raciocínio, re-entra o pensamento conceptual; o herdeiro ex re certa é herdeiro (pensamento conceptual)

8. "Sucessões", $3^{2}$ ed., Rio, Forense, p. 184. 
mas está mais próximo do legatário que o herdeiro em quota abstrata (pensamento tipológico).

Ainda sobre o herdeiro ex re certa, no Direito italiano, Messineo ${ }^{9}$ escreve: "Poichè la determinazione legale della figura del legatario, ricavata per eleminazione, potrebbe, in speciali ipotesi, dar luogo a dubbi, l'art. 588 capov., per eliminarli, ha chiarito che non è legatario, ma erede anche colui, che succeda in beni determinati, $o$ in complesso di beni determinati, quando risulti la corrispondente intenzione del testatore di assegnare quei beni, come quota del patrimonio ereditario, quase separandoli dal resto: c.d. instituzione ex certa re, o in certis rebus" E mais adiante: "L'istituito in certis rebus è erede ad ogni effetto; quindi, anche a quello dell'obbligo del pagamento dei debiti ereditari e dell'esercizio delle varie azioni ereditarie (cfr. $\$ \S 207$ segg.): in special modo, dell'azione di riduzione, se egli sia legittimario"

Também no Direito brasileiro, dúvida não pode haver de que o herdeiro ex re certa é herdeiro, e não, legatário. A lei positiva é expressa em permitir ao testador determinar o conteúdo da quota do herdeiro. Isto está claro quanto ao herdeiro necessário - e o herdeiro necessário, isto é, o que tem direito à reserva, é herdeiro, e não, legatário. $\mathrm{O}$ herdeiro necessário limita quantitativamente a liberdade de testar; ele tem direito à metade dos bens do de cujus (art. 1.721 do Código Civil). Ora, qualquer que seja o critério, inclusive pelo nome, esse herdeiro necessário é herdeiro, e não, legatário; no entanto, nosso Código permite ao testador dar o conteúdo qualitativo dessa legítima dos herdeiros necessários, indo a ponto de facultar até mesmo a conversão dos bens em bens de outras espécies. Veja-se o art. 1.723: "Não obstante o direito reconhecido aos descendentes e ascendentes no art. 1.721, pode o testador determinar a conversão dos bens da legítima em outras espécies, prescrever-Ihes a incomunicabilidade, confiá-los a livre administração da mulher herdeira, e estabelecer-Ihes condições de inalienabilidade temporária ou vitalicia"

É, pois, disposição expressa do Direito Positivo brasileiro a possibilidade de o testador dar o conteúdo da quota do herdeiro, indo aliás, repetimos a ponto de admitir, talvez excessivamente, a própria conversão dos bens em bens de outras espécies e, inclusivamente, quando se trata da própria legítima.

9. "Manuale di Diritto Civile e Commerciale", 9² ed., Milão, Giuffrè, 1962, v. 6, § 173. 
A validade das disposições testamentárias, fixando os bens da quota dos herdeiros, também resulta do art. 1.776 do Código, que permite a partilha testamentária: "É válida a partilha feita pelo pai, por ato entre vivos ou de última vontade, contanto que não prejudique a legítima dos herdeiros necessários" A regra inclui quer a partilha em vida quer a testamentária. A primeira é raríssima, na prática, devendo, quando feita, tomar a forma de doação, isto é, de ato inter vivos. A segunda é ato de última vontade em que os quinhões hereditários já são todos preenchidos pelo testador. A partilha testamentária é instituição de herdeiro ex re certa, com um plus, o de esgotar a quota dos herdeiros, atribuindo-lhes os bens da herança.

Por fim, cumpre lembrar que não é partilha testamentária o ato do testador de fixar regras para serem obedecidas por ocasião da partilha; neste caso, não há partilha (e, portanto, não há atribuição direta de bens), e sim, determinação de regras para serem seguidas quando se for efetuar a partilha. Aqui, após a morte, há, por algum tempo, comunhão hereditária. O trecho de Messineo, a seguir transcrito $^{10}$ trata dessa hipótese. Nela, o testador fixa quotas em abstrato e, simultaneamente, indica os bens que deverão integrá-las (portanto, é a hipótese do art. $733,1^{\text {a }}$ parte, do C.C. italiano, e não, do art. $588,2^{\mathrm{a}}$ parte, do mesmo Código). $\mathrm{O}$ trecho reza: "Il modo di effettuare la divisione (presupposta sempre la comunione ereditaria) e, più precisamente, il modo di formare le porzioni, può essere influenzato in deroga agli artt. 727, 728 e 729 da eventuali apposite "norme", che siano stabilite dal testatore (mediante clausole del testamento) (733 primo comma); il che lascia supporre che il testatore abbia stabilito, in astratto, le quote spettanti ai singoli coeredi (arg. 733 primo comma, in fine) e si tratti di formare le corrispondenti porzioni concrete. Si avverta che tali norme possono, anche, stabilire, sproporzioni fra le porzioni, purchè restino salve le ragioni dei legittimari. Tali norme sono vincolanti (obbligatorie) per $i$ condividenti, salvo che applicandole l'effettivo valore deli beni (concreti), assegnati ai coeredi, riesca non-corrispondente alle quote (astratte), stabilite dal testatore (733 primo comma). Così, é prevista (e disciplinata), uma discrepanza fra singole quote (anche diseguali fra loro: supra) e singole porzioni: ossia, fra criterio di reparto e risultado dello stesso. Prevale la determinazione delle quote (astratte), sulle norme, che siano

10. "Manuale de Direitto Civile e Commerciale", $9^{2}$ ed., Milão, Giuffrè, 1962, v. 6, § 204, n. 8, p. 584 . 

vontade e as supra individualistas da familia. Herdeiro e Legatário

stabilite per la formazione delle porzioni (concrete), in quanto queste ultime sono logicamente un posterius, rispetto alla determinazione delle quote (astratte); e, quindi, ne dipendono. Di qui, il diritto del coerede di non sottostare a quella discrepanza"

Considerando-se a longa formação histórica, com origens diversas, vêse bem que o Direito das Sucessões é bem mais complexo do que parece usualmente nas lições acadêmicas. Como quer que seja, em síntese, independentemente de se tratar de sucessão legítima ou testamentária, entende-se, no Direito brasileiro, por herdeiro, não propriamente quem continua a pessoa do falecido, como sustentavam antigos autores franceses o que, hoje, tem conotações surrealistas -, nem exatamente quem é "sucessor a título universal" qualificação que se torna ambígua nos casos do herdeiro ex re certa e da partilha testamentária e, ainda, no legado de direitos hereditários , mas sim, quem, tomando o lugar do de cujus no patrimônio (ativo e passivo), surge como continuador das relações jurídicas deixadas. Essa condição é fixada pelo testador na sucessão testamentária e pelo legislador na sucessão legítima. Lembre-se que há, na herança, força expansiva; ela, conforme a situação dos fatos, passa a incluir bens não previstos e dívidas não conhecidas, eis que, como universitas, tem conteúdo oscilante. Diferentemente, o legatário recebe bens ou vantagens circunscritos; perante terceiros, o legatário é mero adquirente de bens; não é continuador patrimonial do de cujus.

São Paulo, 16 de janeiro de 2000. 